
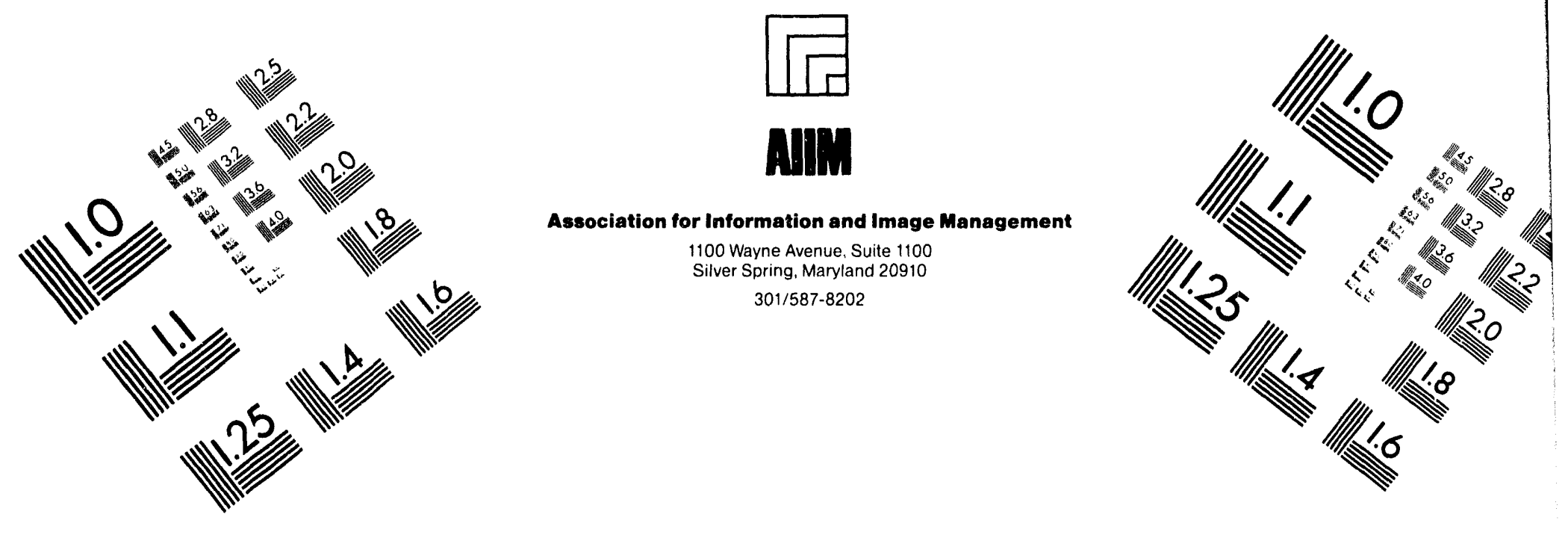

\title{
Centimeter
}

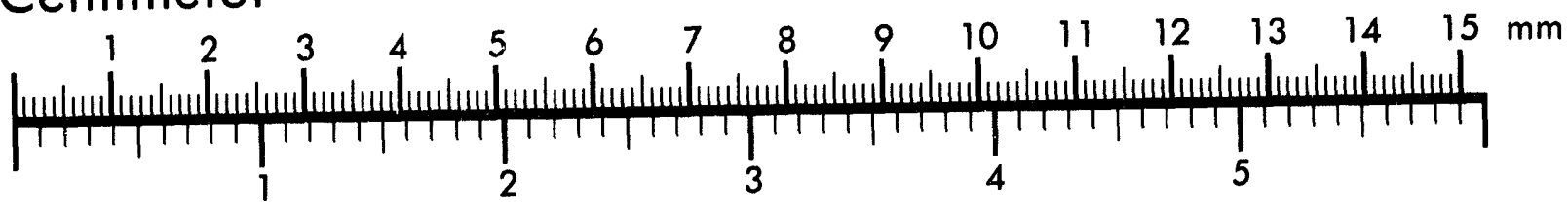

Inches
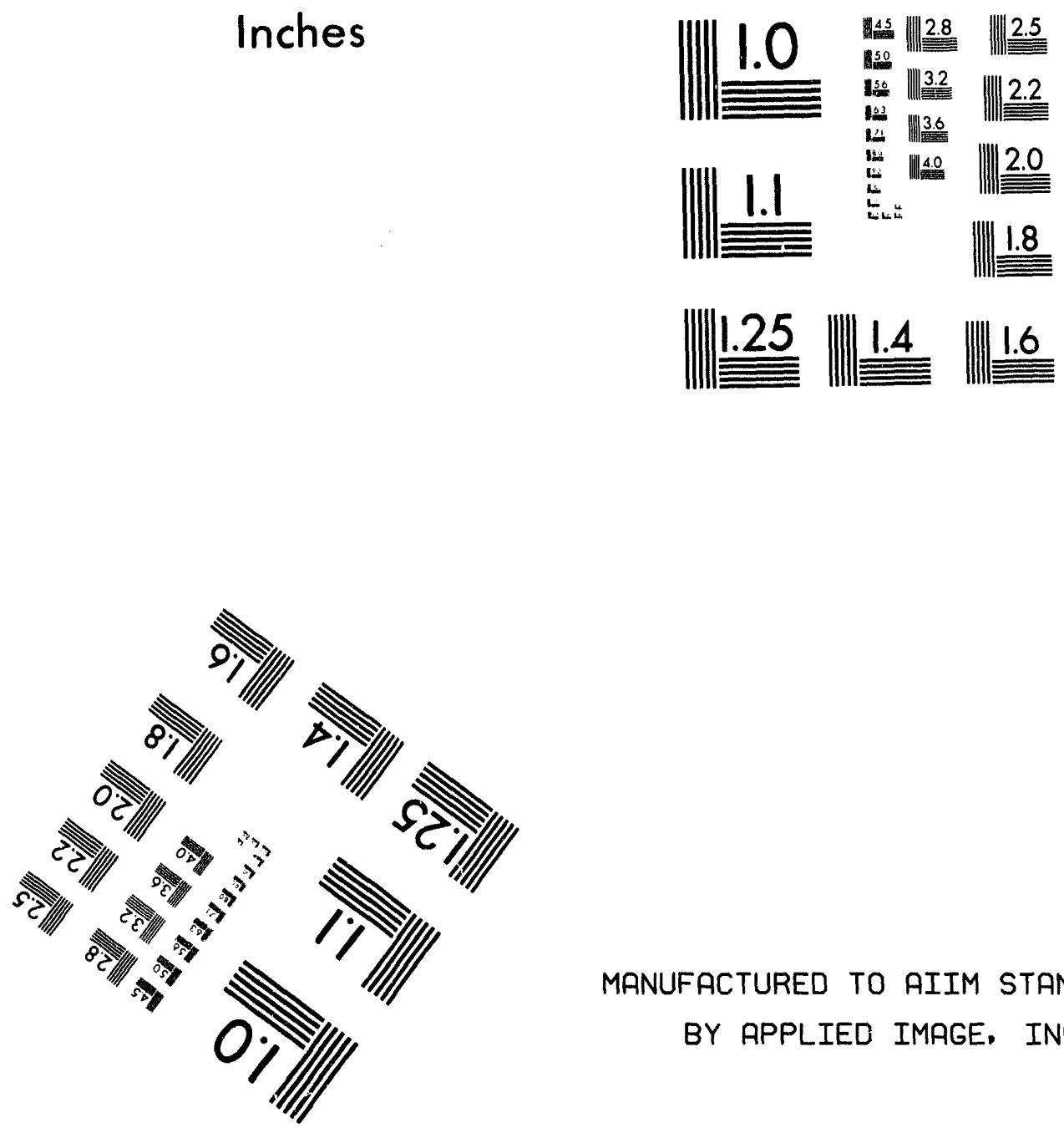

MANUFACTURED TO AIIM STANDARDS

BY APPLIED IMAGE, INC.

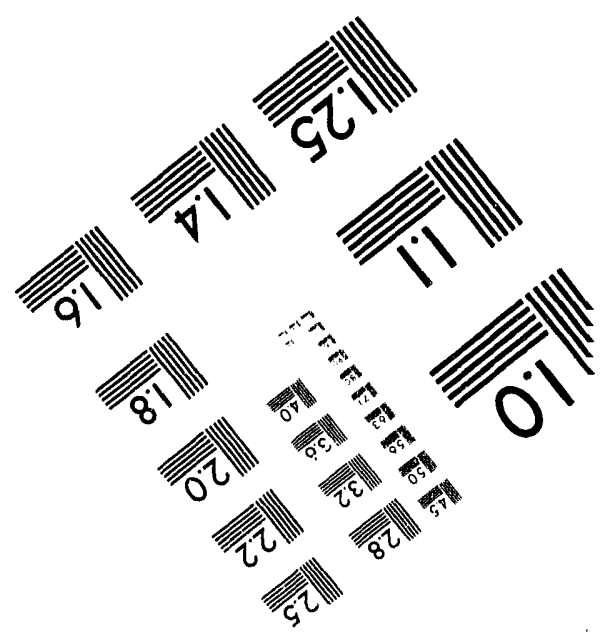



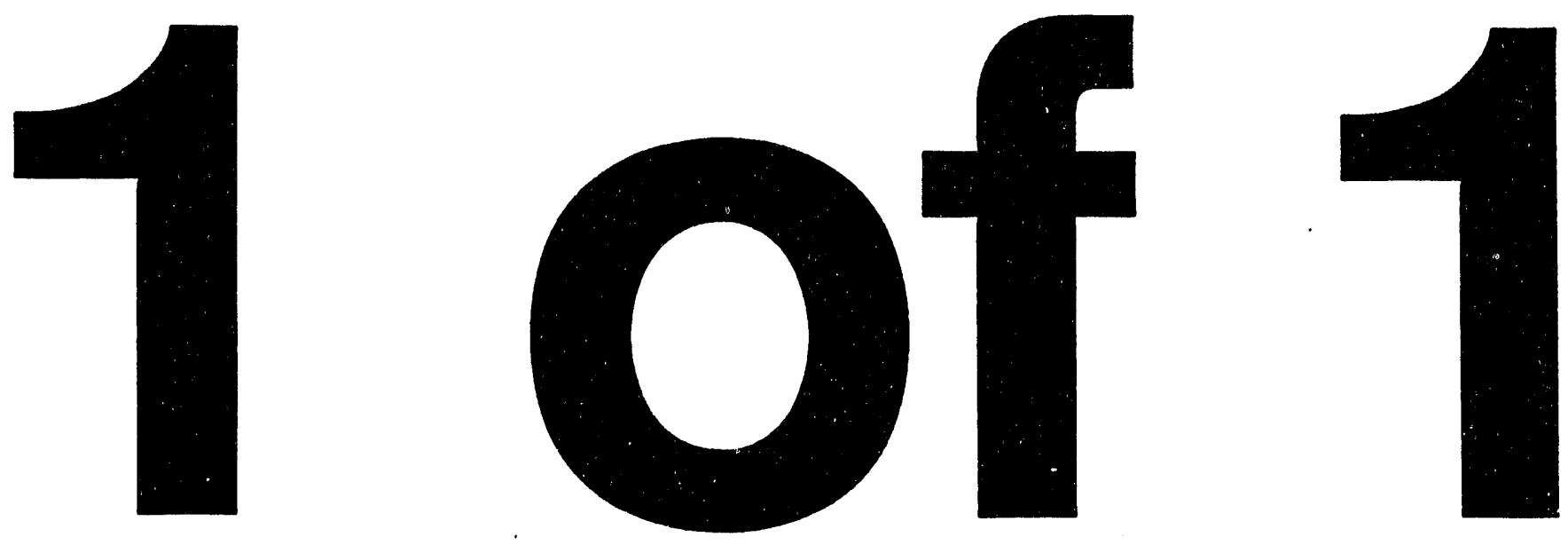
UCRL-JC-115595

PREPRINT

\title{
A High-Power Switch-Mode DC Power Supply for Dynamic Loads
}

\author{
Daniel W. Shimer \\ Arnold C. Lange \\ John N. Bombay
}

This paper was prepared for submittal to the 1994 IEEE Industry Applications Society Annual Meeting Denver, CO

October 2-7, 1994

June 23, 1994

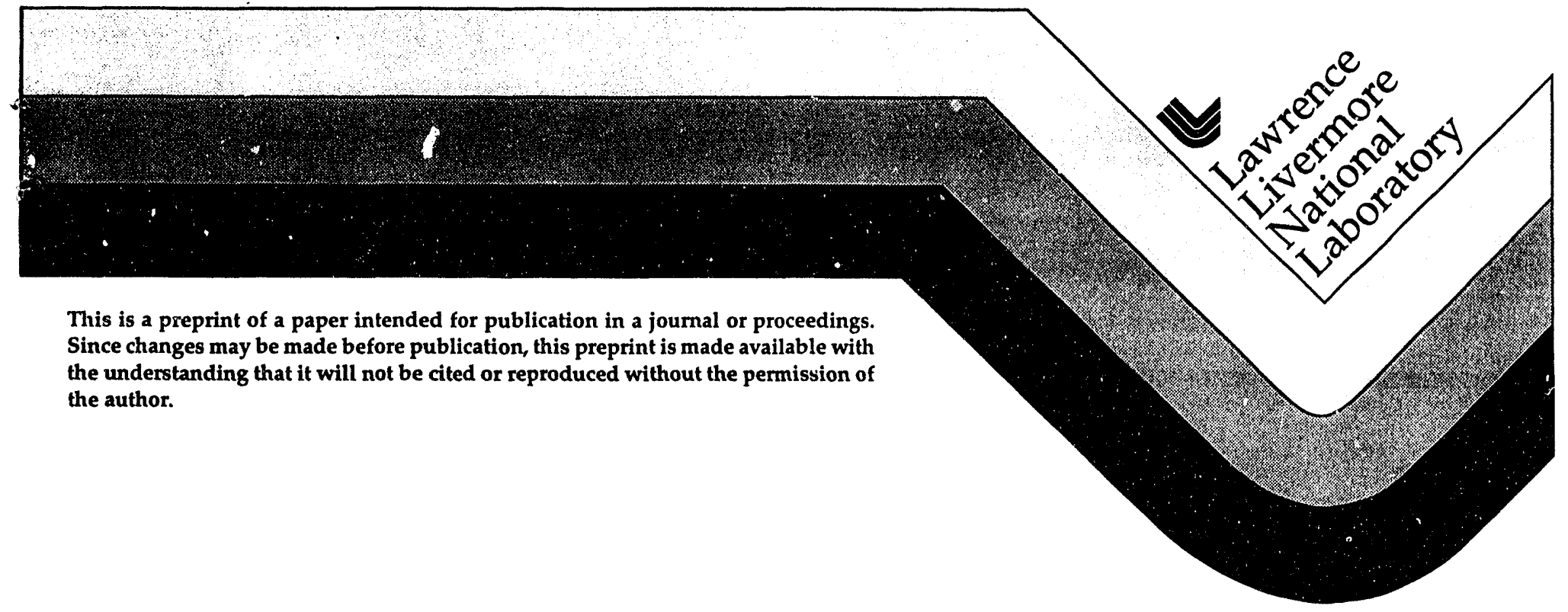


This document was prepared as an account of work sponsored by an agency of the United States Government. Neither the United States Government, nor the University of California, nor any of their employees makes any warranty, express or implied, or assumes any legal liability or responsibility for the accuracy, completeness, or usefulness of any information, apparatus, product, or process disclosed, or represents that its use would not infringe privately owned rights. Reference herein to any specific commercial products, process, or service by trade name, trademark, manufacturer, or otherwise, does not necessarily constitute or imply its endorsement, recommendation, or favoring by the United States Government or the University of California. The views and opinions of authors expressed herein do not necessarily state or reflect those of the United States Government or the University of California, and shall not be used for advertising or product endorsement purposes. 


\section{A HIGH-POWER SWITCH-MODE DC POWER SUPPLY FOR DYNAMIC LOADS*}

\author{
Daniel W. Shimer \\ (Member IEEE) \\ Lawrence Livermore National Laboratory \\ P.O. Box 808, L-459 \\ Livermore, CA 94551
}

\author{
Arnold C. Lange \\ Lawrence Livermore National Laboratory \\ P.O. Box 808, L-459 \\ Livermore, CA 94551
}

John N. Bombay (retired)
Kaiser Engineers
5723 Cabot Dr.
Oakland, CA 94611
Abstract-High-voltage dc power supplies are often required to operate with highly dynamic loads, such as arcs. A switch-mode dc power supply can offer significant advantages over conventional thyristor-based dc power supplies under such conditions. It can quickly turn off the supply to extinguish the arc, and it can quickly recover after the arc. It has a relatively small output filter capacitance, which results in small stored energy available to the arc. A 400-kW, 50-kV switch-mode dc power supply for an electron-beam gun that exploits these advantages was designed and tested. It uses four $100-\mathrm{kW}$, current-source-type dc-dc converters with inputs in parallel and outputs in series. The dc-dc converters operate at $20 \mathrm{kHz}$ in the voltage regulator part and $10 \mathrm{kHz}$ in the inverter, transformer, and output rectifier part of the circuit. Insulated gate bipolar transistors (IGBTs) are used as the power switches. Special techniques are used to protect the power supply and load against arcs and hard shoits. The power supply has an efficiency of $93 \%$, an output voltage ripple of $1 \%$, and fast dynamic response. In addition, it is nearly one-third the size of conventional power supplies.

\section{INTRODUCTION}

High-voltage dc power supplies often must operate with frequent arcing, fast current demands, or high slew rates. Applications include electron-beam guns, plasma processes, electrostatic precipitators, and capacitor chargers. Present-day commercial dc power supplies with outputs above $-10 \mathrm{~kW}$ are phase-controlled, $60-\mathrm{Hz}$ rectifiers using thyristors. Such a power supply responds slowly to arcs and load changes. It is also physically large because of the $60-\mathrm{Hz}$ transformer and has a low input power factor. Another power supply sometimes used is the series-pass regulator with a tetrode vacuum tube used both for regulation and for fast shutdown during arcs. This power supply has a maximum efficiency of only $\sim 80 \%$ and requires substantial maintenance because of the vacuum tube.

The power supply described here uses switch-mode techniques to eliminate deficiencies of conventional designs. It is designed to drive an electron-beam gun with a regulated output of 0 to $-50 \mathrm{kVdc}$ and 0 to $400 \mathrm{~kW}$, and with frequent gun arcing. It is made of four $100-\mathrm{kW}$ dc-dc converter sections (see Fig. 1). Insulated gate bipolar transistors (IGBTs) are the power switches used in the dc-dc converters.

The power supply was developed as part of the Uranium Atomic Vapor Laser Isotope Separation (U-AVLIS) program at the Lawrence Livermore National Laboratory. It is currently operational and is used to support the AVLIS advanced vaporizer [1].

* This work was performed under the auspices of the U.S. Department of Energy by the Lawrence Livermore National Laboratory under Contract No. W-7405-Eng-48.

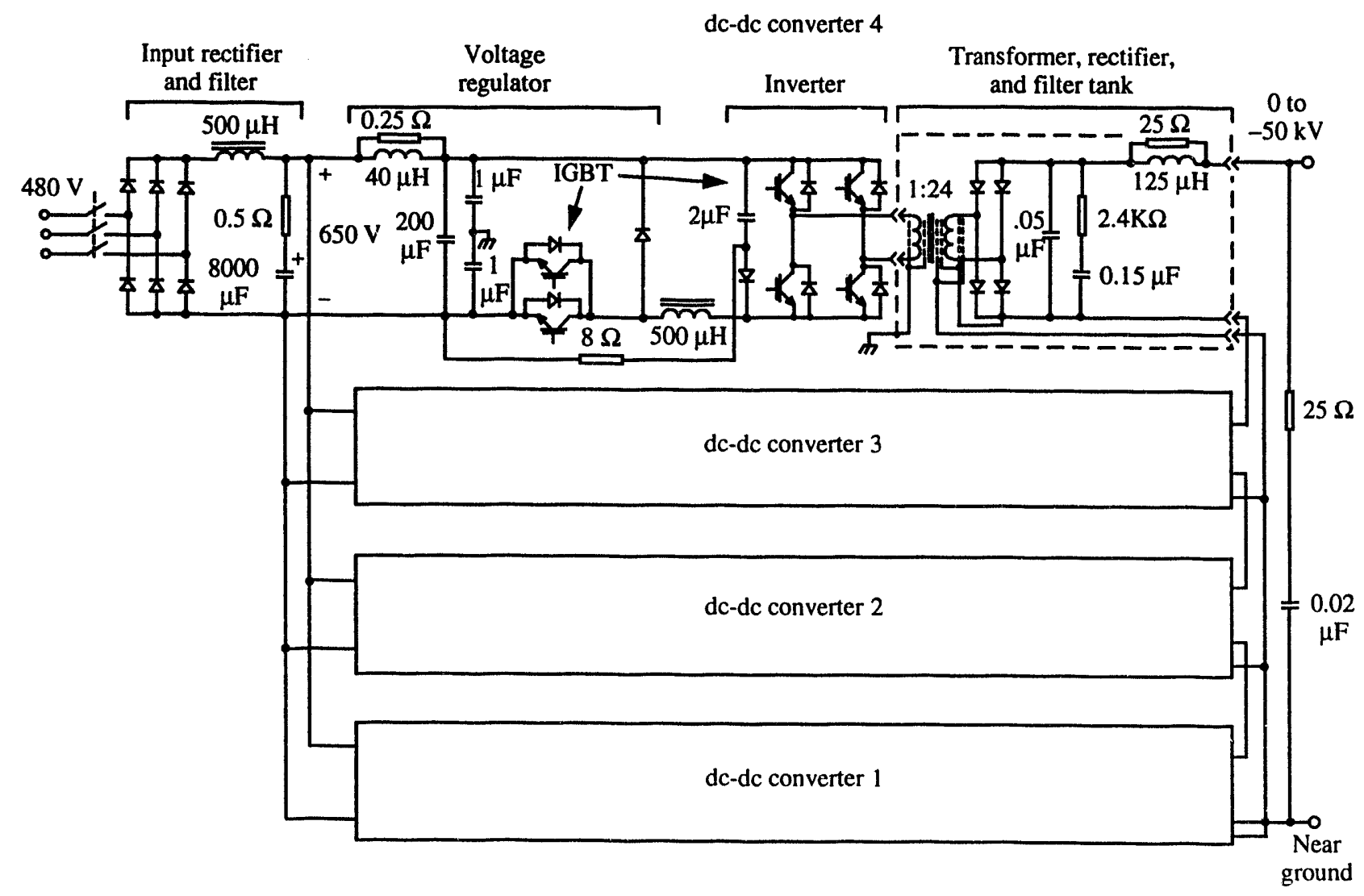

Fig. 1. Simplified power circuit schematic of $400-\mathrm{kW}$ e-beam gun power supply. 


\section{DESIGN APPROACH}

The power supply was designed specifically to meet the requirements of the electron-beam gun and its supporting systems. These are listed in Table I.

TABLE I

REQUIREMENTS

Voltage ripple

Stored energy from power supply during a gun arc

Arc response

$\leq 2 \%$ peak-to-peak, full scale to maintain a focused beam.

$<25 \mathrm{~J}$, to limit long-term damage caused by arcs near the gun.

- Tum off power within $5 \mu$ s after initiation of an arc.

-50- to 250-ms off-time to allow arc to extinguish.

Rise time during turnon $<5 \mathrm{~ms}$ to prevent heating of adjacent structures.

\begin{tabular}{ll} 
Efficiency & $\geq 90 \%$ \\
Power factor & $\geq 0.95$ \\
Cooling & Primarily low-conductivity water. \\
Packaging & Modular, service on bench. \\
Distance from gun & $>100 \mathrm{ft}(30 \mathrm{~m})$ \\
\hline
\end{tabular}

Several of these requirements push the design toward a switch-mode power supply, which requires only a small output filter capacitance because of its high-frequency operation. It can meet the conflicting voltage ripple and maximum stored energy requirements without needing a complex and lossy series-pass regulator. A switch-mode power supply also can easily meet the response-time requirement for turning off the power supply output during an arc and the rise-time requirement during turnon of the power supply. The efficiency, power factor, and modularity requirements are also consistent with a switch-mode design.

The design chosen uses multiple dc-dc converters fed from the ac line through a diode rectifier and filter. They are phase shifted from each other to raise the ripple frequency and reduce the peak currents at the input and output. At the time of the design, the ratings of the available IGBTs limited the dc-dc converter size to $100 \mathrm{~kW}$. The dc-dc converter selected is a modified version of the pulse-width-modulated, current source type with separate regulator and inverter sections [2]. It uses rectangular waveshapes, which minimize the filtering needed at the output. A switching frequency of $10 \mathrm{kHz}$ was chosen for the inverter to control switching losses to an acceptable level. A switching frequency of $20 \mathrm{kHz}$ for the voltage regulator was selected to eliminate audible noise in the filter inductor.

\section{DESCRIPTION OF POWER SUPPLY}

The high-voltage e-beam power supply consists of an input rectifier and filter followed by four dc to dc converter sections, as shown in Fig. 1. The inputs of all four dc-dc converters are in parallel, and the outputs are in series. Each dc-dc converter consists of a voltage regulator, inductor, inverter, transformer, rectifier, and filter. It is packaged in two parts, the regulator/inverter modu'e and the transformer/rectifier module. The voltage regulator operates witn a variable on/off ratio to control the output voltage. The inverter operates with a fixed square waveform. Each dc-dc converter produces an output voltage $\leq 12.5 \mathrm{kV}$. All four converters are phase-shifted from each other resulting in an $80-\mathrm{kHz}$ ripple at the power supply output. Idealized waveforms of the currents and voltages at full and half power are shown in Fig. 2.
During a load arc, the output current is sensed, which turns off the voltage regulator IGBTs to stop power flow from the input line. Simultaneously, the inverter IGBTs all turn on, which short out the transformer primary. This minimizes transfer of stored energy from the primary side and from the transformer into the load arc.

The power supply is divided into modules, each removable for repair and replacement. Fig. 3 shows the arrangement of the chassis and modules in the rack. The input power source for the power supply is $480 \mathrm{Vac}$, three-phase. Utility power for the controls, fans, and pumps is derived from this one source. The primary method of cooling in the power supply is low-conductivity cooling water (LCW).

Fig. 4 is a top view of a regulator/inverter module connected to a transformer/rectifier module. The transformer, rectifier stacks, filter components, and interconnecting wires are mounted inside a stainlesssteel tank and are immersed in silicone dielectric fluid [3] for electrical insulation and cooling. The fluid is circulated through an oil-to-water heat exchanger to transfer the heat to the LCW system.

\section{Input Rectifier and Filter}

The input rectifier and filter section includes the input contactor, diode bridge rectifier, and part of the input dc filter network. It also includes protective fuses and varistors, current and voltage monitors, and control transformers, which are not shown in Fig. 1. The input contactor is a NEMA size 6, rated at $600 \mathrm{Vac}$ and $540 \mathrm{~A}$. The diodes are conventional, commercially available, water-cooled assemblies.

The input filter network includes the main filter inductor of $500 \mu \mathrm{H}$, the filter damping network of $0.5 \Omega$ in series with $8000 \mu \mathrm{F}$, and the parallel combination of the $200-\mu \mathrm{F}$ capacitors in the input of the four dc-dc converter sections. The filter inductor is sized to obtain a current ripple of $15 \%$ peak-to-peak at $360 \mathrm{~Hz}$. The capacitors are sized to obtain a voltage ripple of $10 \mathrm{~V}$ peak-to-peak at $20 \mathrm{kHz}$ at the dc-dc converter input. The damping network uses the design method of Praeg [4] to provide a critically damped filter.

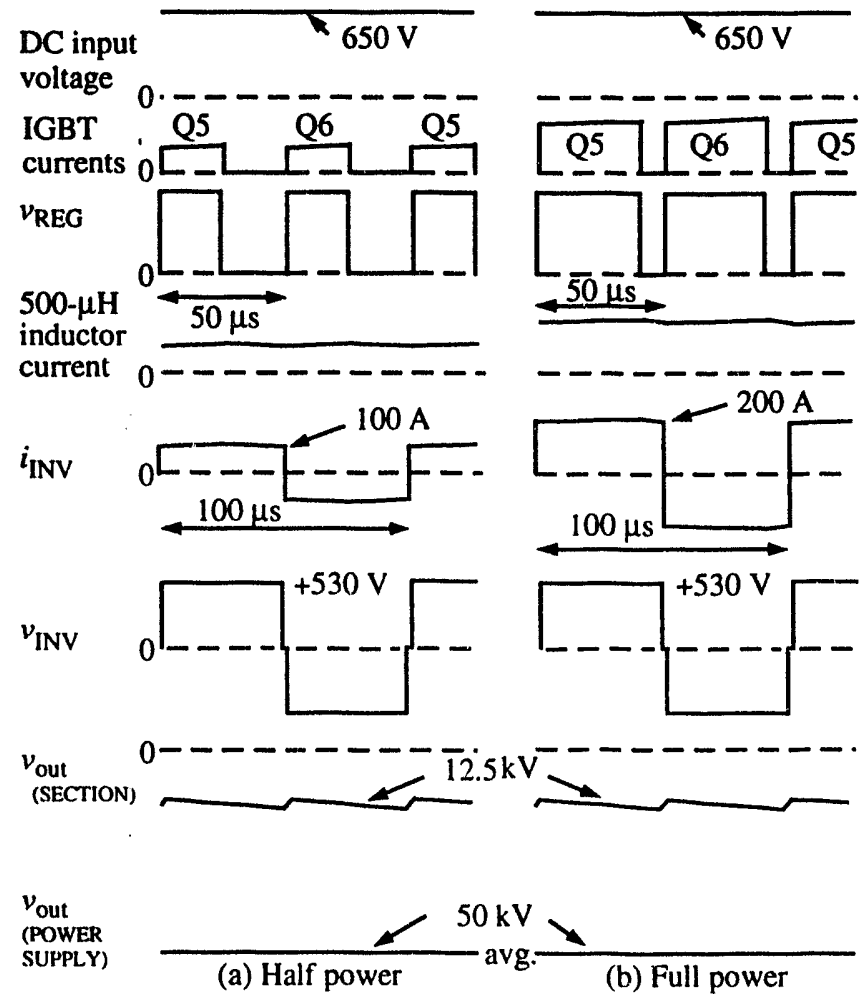

Fig. 2. Idealized power supply voltage and current waveforms at half and full power. s. 


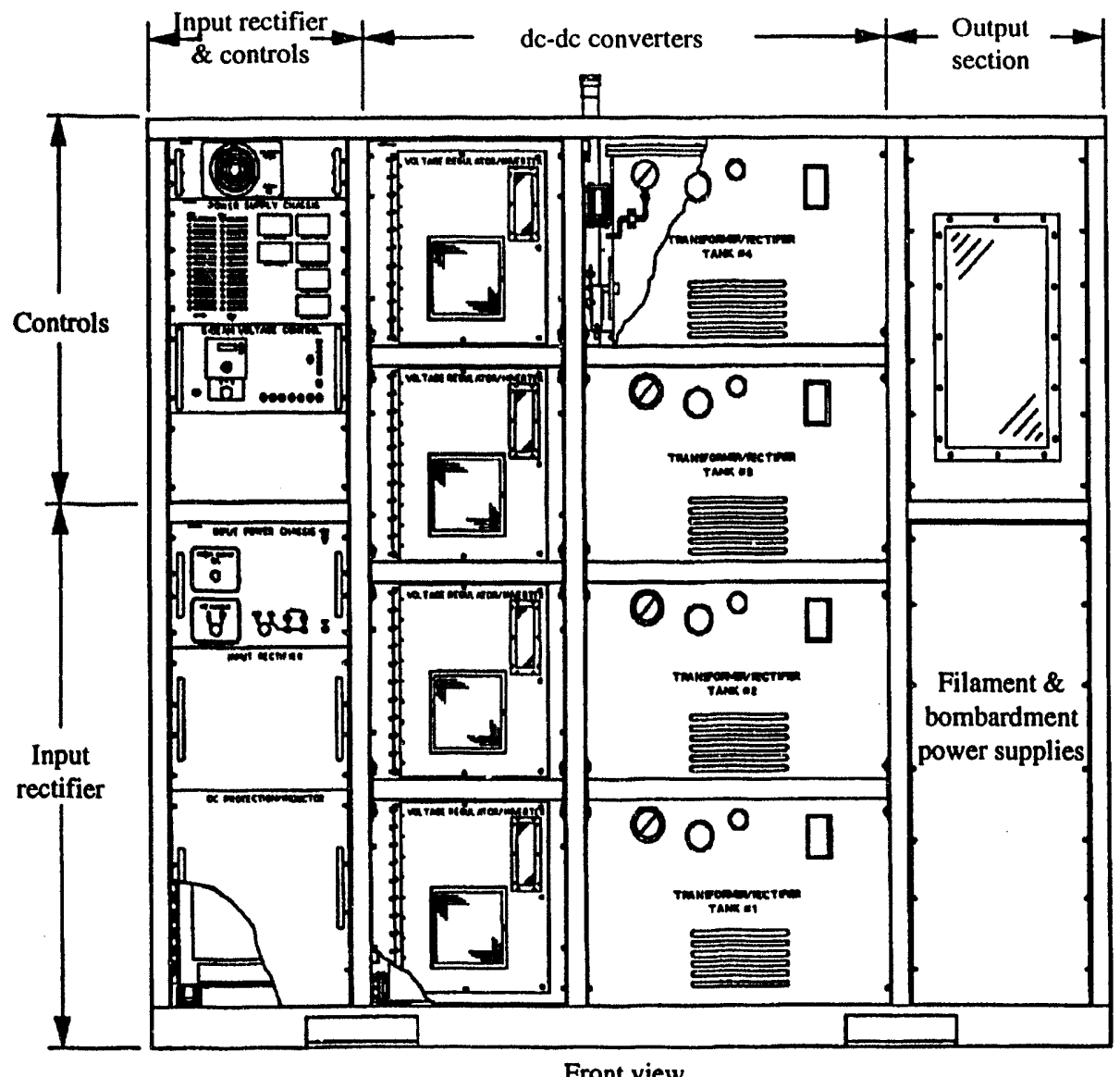

Front view

Fig. 3. Power supply layout.

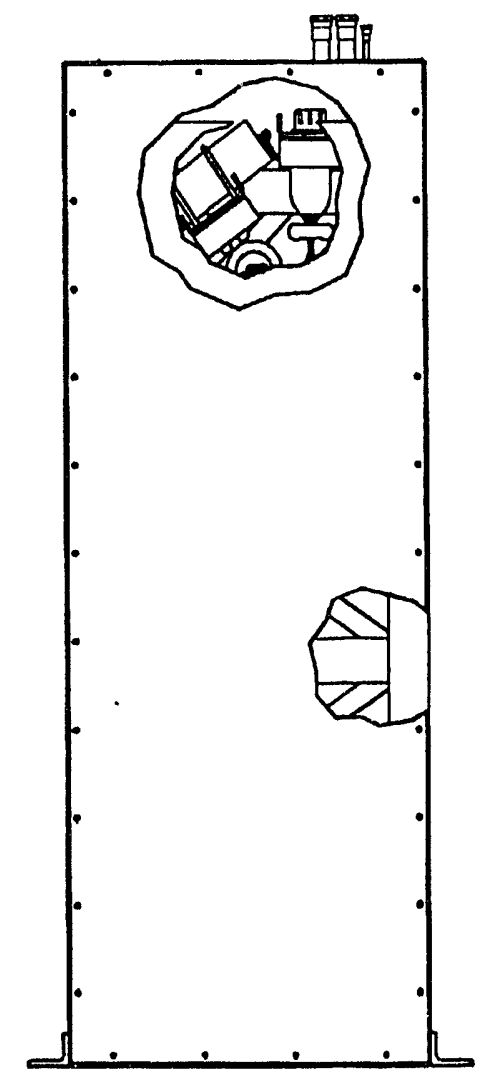

Right side view

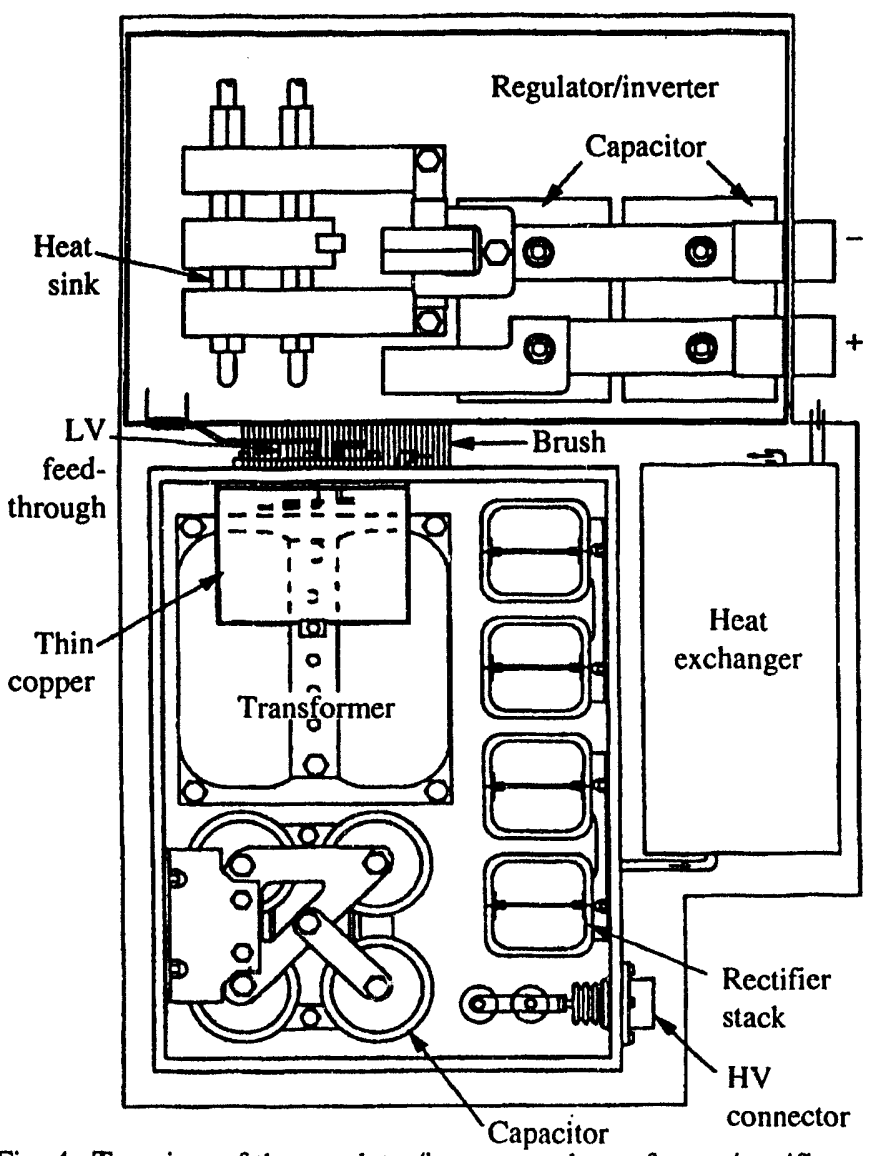

Fig. 4. Top view of the regulator/inverter and transformer/rectifier, showing the low-inductance return points.

\section{Regulator}

The power circuit schematic of the regulator is shown in Fig. 5 along with the inverter and inductor. The input consists of a decoupling network formed by R7 and L3 connected to filter capacitor $\mathrm{C} 7$. The regulator portion consists of Q5 and Q6 IGBTs, the free-wheeling diode network made up of CR10-CR13, and the associated snubber networks. The inverter network, discussed in the next section, consists of Q1-Q4 IGBTs, the snubber networks for these IGBTs, and the voltage clipper network composed of $\mathrm{Cl}$ and $\mathrm{CR} 17$. A 500- $\mu \mathrm{H}$ inductor couples the voltage regulator to the inverter and provides a current source drive for the inverter.

Decoupling Network: The network formed by L3 and R7 in parallel is used to damp ringing between the input circuits of the four regulators. The cable inductance between the input filter damping network and each regulator is 1 to $2 \mu \mathrm{H}$. The resonant network formed by these inductances and the four $200-\mu \mathrm{F}$ input capacitors is damped by the $0.25-\Omega$ resistor in parallel with the $40-\mu \mathrm{H}$ inductor.

Regulator Switches: IGBTs Q5 and Q6 alternatively conduct, each at a frequency of $10 \mathrm{kHz}$. This alternating conduction is used to enable monitoring of the current at the input with a current transformer. The digital timing circuitry and the analog feedback control circuitry provide a controlled conduction time command to Q5 and Q6 gate drivers. This results in a $650-\mathrm{V}$ pulse train at a frequency of $20 \mathrm{kHz}$ with a variable conduction time at the voltage regulator output. The conduction time varies from 2 to $43 \mu \mathrm{s}$, as commanded by the controls. The voltage pulse train produces a buildup of dc current in the $500-\mu \mathrm{H}$ inductor L2, depending on its average value and the average voltage reflected back from the load. During the time intervals when Q5 or Q6 are conducting, the current in L2 flows through Q5 and Q6 from the input capacitor $\mathrm{C} 7$ and the input source.
$-$ $\therefore-$ 


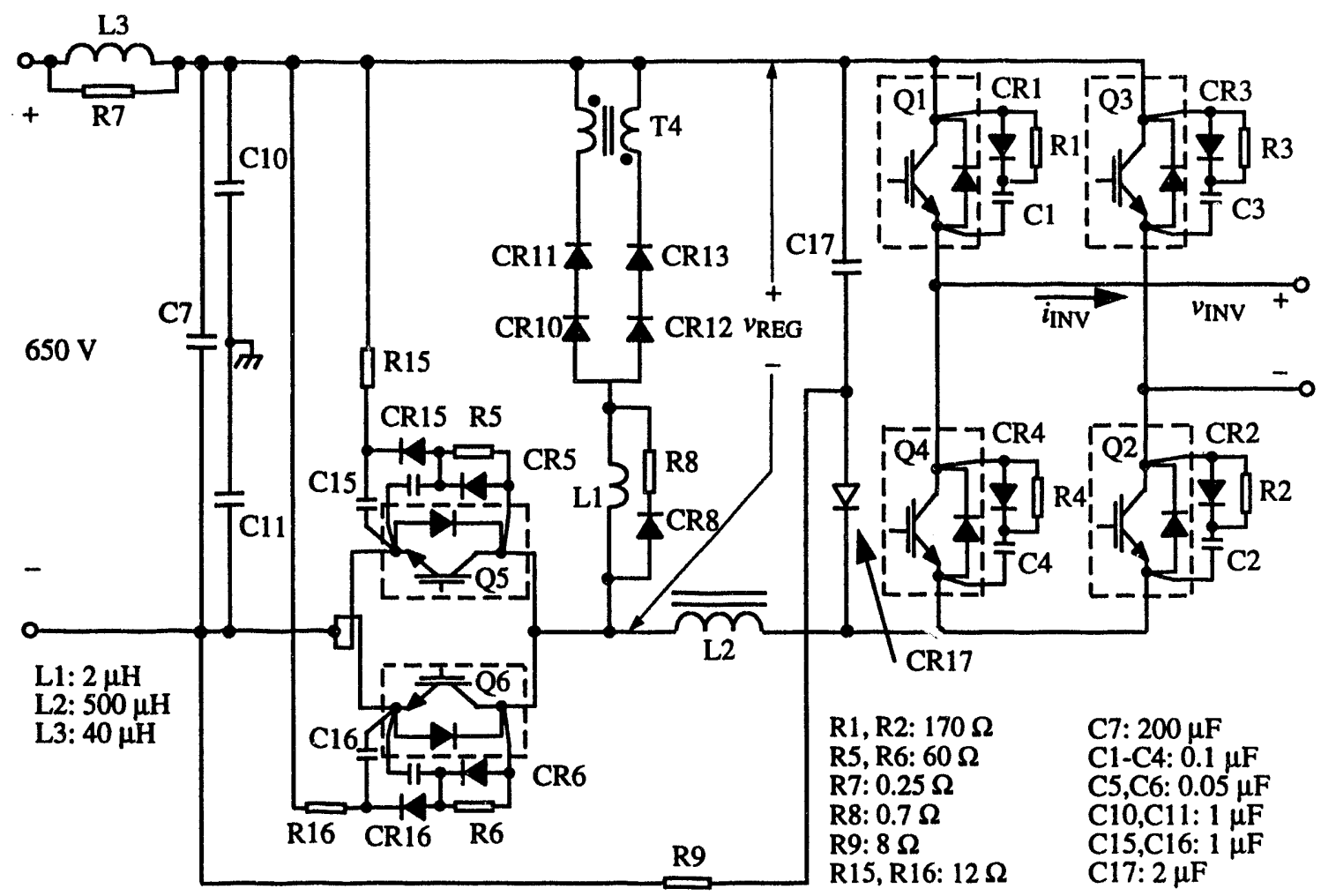

Fig. 5. Power circuit of the regulator/inverter.

When both Q5 and Q6 are not conducting, the current in L2 flows through the bypass diode network formed by CR10-CR13, coupling transformer T4, inductor $\mathrm{L} 1$, resistor $\mathrm{R} 8$, and diode CR8. Transformer T4 is constructed from one turn through a ferrite core and is used to improve current-sharing during recovery of CR10-CR 13. Inductor L1, resistor $\mathbf{R 8}$, and diode $\mathrm{CR8}$ are to slow the transfer of current from the bypass diode path to Q5 or Q6 during turnon of Q5 or Q6. This reduces turnon losses in Q5 and Q6 [5].

All IGBTs in the regulator, as well as the inverter discussed below, have snubber networks consisting of a diode, a resistor, and a capacitor in parallel with them. They are formed from the diodes CR1-CR6, resistors $\mathrm{R} 1-\mathrm{R} 6$, and capacitors $\mathrm{Cl}-\mathrm{C} 6$. They reduce the tumoff losses in the IGBTs but dissipate substantial power themselves in the resistors. IGBTs Q5 and Q6 have additional biased clamping networks formed by CR15, C15, and R15 for Q5 and by CR16, C16, and R16 for Q6. These networks limit the peak voltage across Q5 and Q6 during turnoff to approximately $200 \mathrm{~V}$ above the input dc bus, or approximately $900 \mathrm{~V}$.

The IGBTs used for $\mathrm{Q} 1-\mathrm{Q} 6$ in the regulator and inverter are rated at $300 \mathrm{~A}, 1200 \mathrm{~V}$. They are of the first-generation type. The diodes used in the regulator and inverter, CR1-CR17, are fast-recovery type, rated at $85 \mathrm{~A}, 1000 \mathrm{~V}$, and $1.3 \mu \mathrm{C}$ reverse recovered charge. The resistors are constructed with a metal film on a ceramic tube. They are directly water cooled. The IGBTs and diodes mount on cold-plate type, water-cooled aluminum heat sinks.

Common-mode Return: Capacitors $\mathrm{C} 10$ and $\mathrm{C} 11$ provide a highfrequency connection from each input bus to the grounded chassis of the regulator/inverter module. Capacitive currents from the primary shield of the transformer circulate through the low-inductance bus in the transformer/rectifier tank, through the brass brushes to the regulator/inverter chassis ground, and finally to each input bus. This defined, low-inductance path minimizes stray currents and common-mode currents in the power supply load.

\section{Inverter}

Inverter IGBTs Q1-Q4 each conduct for approximately half the time at a frequency of $10 \mathrm{kHz}$. The pairs formed by $\mathrm{Q} 1$ and $\mathrm{Q} 2$ and by Q3 and Q4 conduct together. A 2- $\mu$ s overlap occurs each cycle when all four IGBTs are gated on simultaneously. This overlap time aids in the transfer between IGBT pairs and output polarity. The biased clamping network formed by $\mathrm{Cl} 7, \mathrm{CR} 17$, and $\mathrm{R} 9$ limits the voltage across the inverter dc bus during transfer of output polarity under heavy loads.

The voltage-clamping network differs from the network used in [2] and is more suitable for high-power applications. It can be located very close to the inverter input bus and therefore has much lower lead inductance. An idealized model of the operation of this clamping network during current polarity transitions is described below for normal operation and for hard load shorts. Results are also shown from a PSpice circuit simulation, which uses a realistic model.

Idealized Model-Normal Operation: Fig. 6 is an idealized model of the inductor, inverter, clamping network, and the transformer-rectifier load. The voltage source $v_{\mathrm{p}}$ represents the output of the rectifier and filter capacitor, reflected to the transformer primary. Depending on the current polarity, $v_{\mathrm{p}}$ will equal $\pm V_{\mathrm{o}} / n$, where $V_{\mathrm{o}}$ is the output voltage and $n$ is the turns ratio. Prior to time $t_{1}$, transistors Q3 and Q4 are conducting and $i_{\mathrm{INV}}=-I$ and $v_{\mathrm{p}}=-V_{\mathrm{o}} / n$. Capacitor $\mathrm{C}_{\mathrm{CL}}$ is charged to the input dc voltage, $V_{\mathrm{IN}}$, which is nominally $650 \mathrm{~V}$. At $t=t_{1}$, transistors Q1 and Q2 are gated on in addition to Q3 and Q4. The voltage source $v_{\mathrm{p}}$ drives $i_{\mathrm{INV}}$ to zero and the currents in Q1-Q4 to $I / 2$ at $t=t_{2}$, identically to that described in [2]. At $t=t 3$, transistors Q3 and Q4 are gated off. The transformer leakage inductance, $L_{\mathrm{p}}$, is at zero current at $t=t_{3}$ and cannot suddenly increase. The current $I$ in inductor $L$ must transfer to the clamp formed by $\mathrm{C}_{\mathrm{CL}}$ and $\mathrm{D}_{\mathrm{Cl}}$. The voltage across $\mathrm{C}_{\mathrm{CL}}$ exceeds $v_{\mathrm{p}}=+V_{\mathrm{o}} / n$ and forces $i_{\mathrm{INV}}$ to increase. It eventually reaches $I$ at $t=t_{4}$. The following equations describe the relationships: 

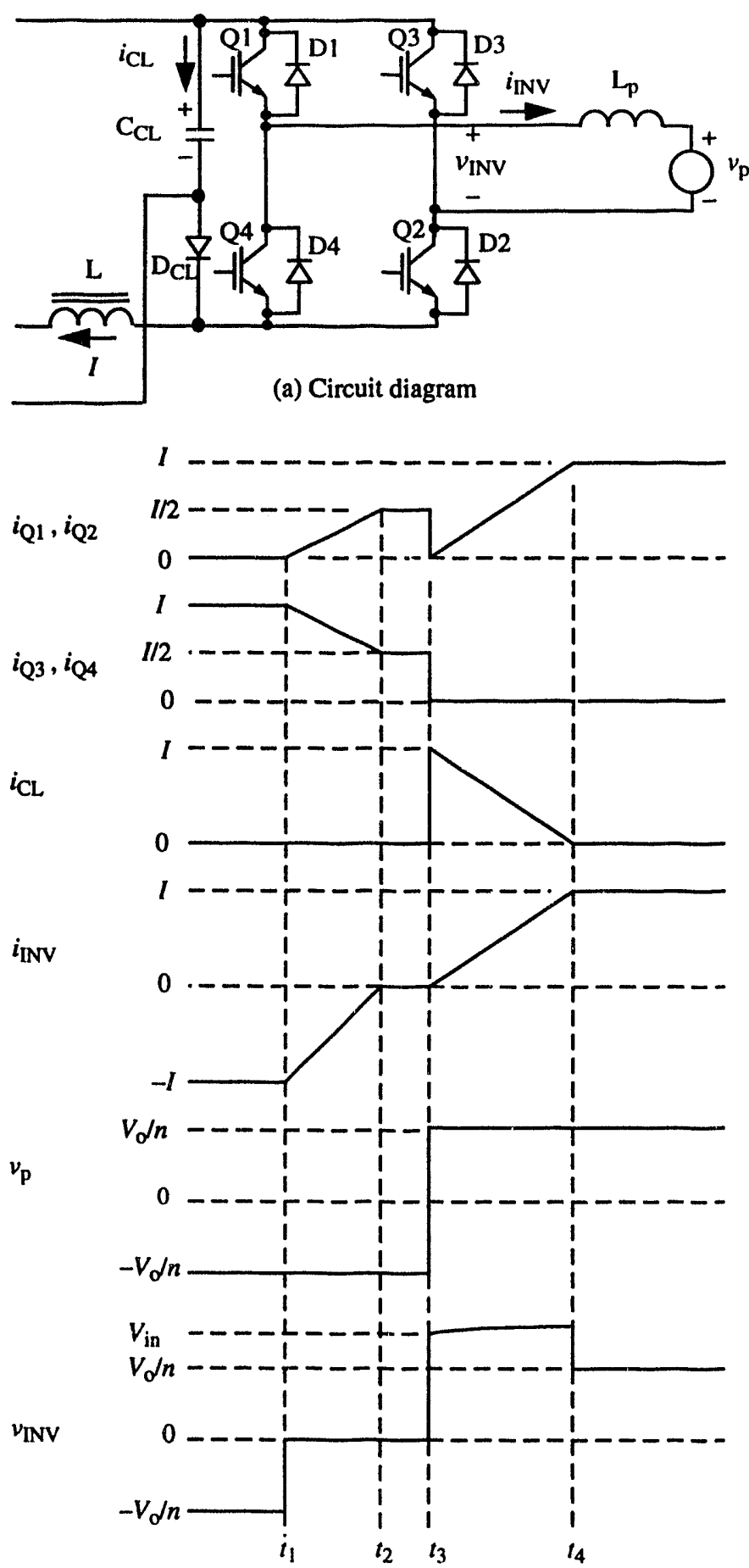

(b) Waveforms

Fig. 6. Inverter ideal model during normal operation.

$$
\begin{gathered}
t_{2}-t_{1}=\frac{L_{\mathrm{p}} I}{V_{\mathrm{o}} / n}, \\
t_{3}-t_{1}=2 \mu \mathrm{s}, \\
t_{4}-t_{3}=\frac{L_{\mathrm{p}} I}{\left(V_{\mathbb{N}}-V_{\mathrm{o}} / n\right)} \text { (approximate). }
\end{gathered}
$$

Idealized Model-Extended Load Short: Fig. 7 shows a model and waveforms for transition of the inverter output current polarity during
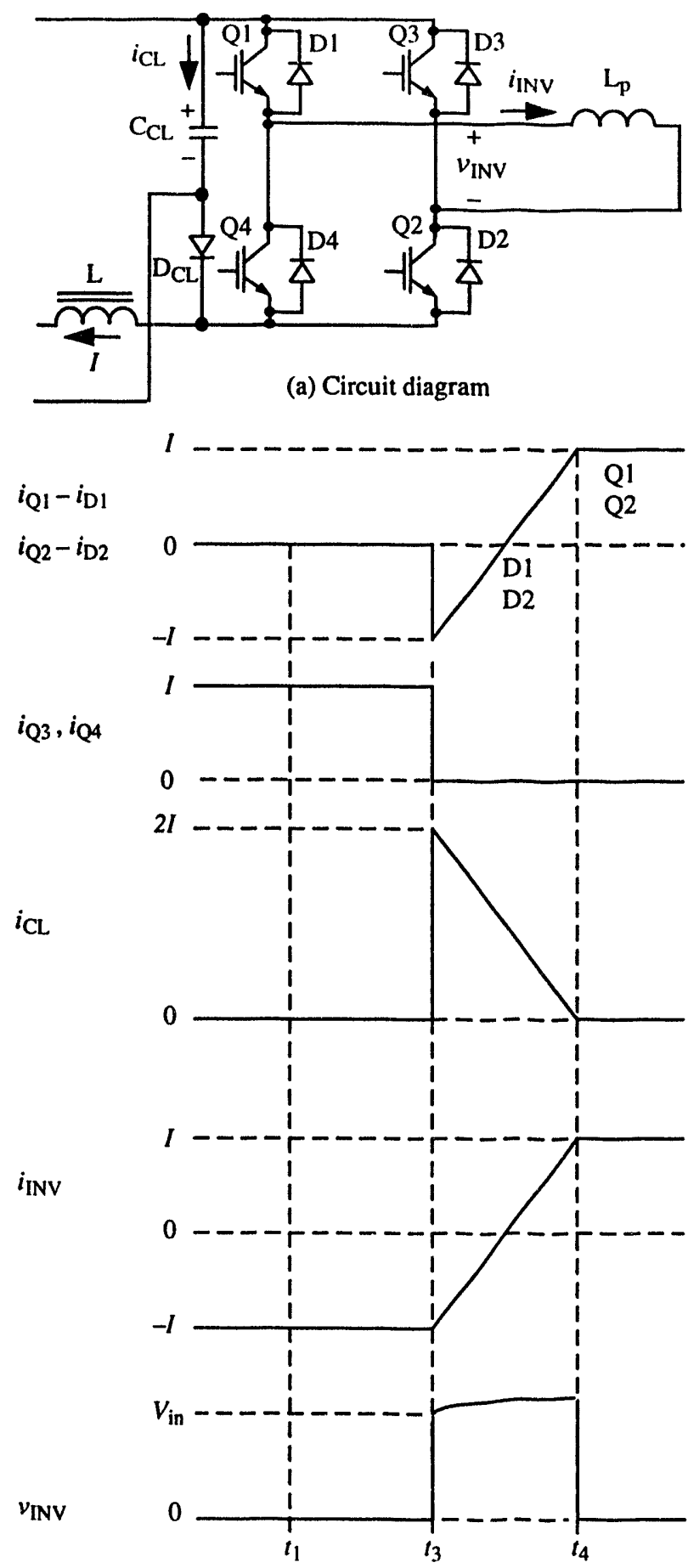

(b) Waveforms

Fig. 7. Inverter ideal model during an extended load short.

an extended, or hard, load short. The circuit operation differs from the previous case because $v_{\mathrm{p}}= \pm V_{0} / n=0$. Before $t=t_{1}$, transistors Q3 and Q4 are conducting, $i_{\mathrm{INV}}=-I$, and $v_{\mathrm{INV}}=0$. Capacitor $\mathrm{C}_{\mathrm{CL}}$ is charged to $V_{\mathrm{IN}}$, as in the previous case. At $t=t_{1}, \mathrm{Q} 1$ and Q2 are gated on. However, since $v_{\mathrm{p}}=0$, the currents do not change. At $t=t_{3}, \mathrm{Q} 3$ and Q4 are gated off. The current $I$ in $\mathrm{L}_{\mathrm{p}}$ continues, but now its path is through diodes $\mathrm{D} 1$ and $\mathrm{D} 2$ and through the clamp $\mathrm{C}_{\mathrm{CL}}$ and $\mathrm{D}_{\mathrm{CL}}$. In addition, the current in $L$ is now forced through $C_{C L}$ and $D_{C L}$. The voltage across $\mathrm{C}_{\mathrm{CL}}$ forces $i_{\mathrm{INV}}$ to change direction. At $t=t_{4}$, the current in Q1, Q2, and $\mathrm{L}_{\mathrm{p}}$ reaches $I$. For this mode of operation, the following equations hold: 


$$
\begin{gathered}
t_{3}-t_{1}=2 \mu \mathrm{s}, \\
t_{4}-t_{3}=\frac{2 L_{\mathrm{p}} I}{V_{\mathrm{IN}}} \text { (approximate). }
\end{gathered}
$$

Realistic Models: For the e-beam power supply, ideal models do not adequately describe the operation. Because of the high-voltage between the transformer windings and the shields, the capacitance between the transformer secondary and transformer secondary shield stores a significant amount of energy. During polarity transition, the energy stored in this capacitance rings with the energy stored in the transformerleakage inductance. Fig. 8 shows a more realistic model, which includes this shield capacitance.

The entire dc-dc converter was simulated using PSpice. This model includes the snubber networks, stray inductances, and transformer-secondary-shield capacitances. Figs. 9 and 10 show the simulated inverter output voltage and current and the clamping-network current during normal- and extended-load short conditions.

\section{Transformer}

The transformer/rectifier contains the transformer, rectifier, and output filtering (see Fig. 11). The transformer has several special design requirements: (1) square-wave input voltage of $520 \mathrm{Vpk}$ at $10 \mathrm{kHz}$, a turns ratio of 24 , continuous output of $100 \mathrm{~kW}$, and isolation between the output and ground of $50 \mathrm{kVdc}$; (2) low-leakage inductance to achieve acceptable power losses in the inverter and to meet the output voltage ripple specification without exceeding the filter capacitance limit; (3) control of conductor and core ac losses at $10 \mathrm{kHz}$ to an acceptable level; (4) one-turn tertiary winding in the controls to derive a voltage feedback signal for the dc-dc converter section output.

The transformer core consists of six cut $\mathrm{C}$-cores wound from 0.001-in. (0.025-mm)-thick, Permalloy 80 (80\% Ni, 4\% Mo) tape, with a cross section of $1 \times 1.5$ in. $(2.54 \times 3.81 \mathrm{~cm})$ and with a window of $4 \times 7$ in. $(10.2 \times 17.8 \mathrm{~cm})$. The peak-to peak change in flux density was selected to be $0.35 \mathrm{~T}$. The windings consist of 16 turns of $0.010-x$ 6 -in. $(0.025-\times 15.3-\mathrm{cm})$ copper foil for the primary and 384 turns of \#16 AWG copper magnet wire for the secondary. The principal insulation used consisted of various thicknesses of aramid paper (Nomex), 6.5 in. $(16.5 \mathrm{~cm})$ wide, in combination with silicone dielectric fluid. A maximum design stress of $200 \mathrm{~V} / \mathrm{mil}$ was used.

Leakage Inductance: Low transformer-leakage inductance is accomplished by using a pair of shell-type windings, each with a large ratio between the height and thickness. Each secondary winding has two layers of \#16 AWG wire separated from each other by 0.25 -in. (6.4-mm) spacers. This provides space for dielectric fluid flow for cooling without compromising the low-leakage-inductance criteria. The leakage inductance is $2.8 \mu \mathrm{H}$, calculated by the method of Schaefer [6]. The measured inductance is $4.5 \mu \mathrm{H}$. The higher measured value is caused by a looser winding construction than assumed in the calcula-

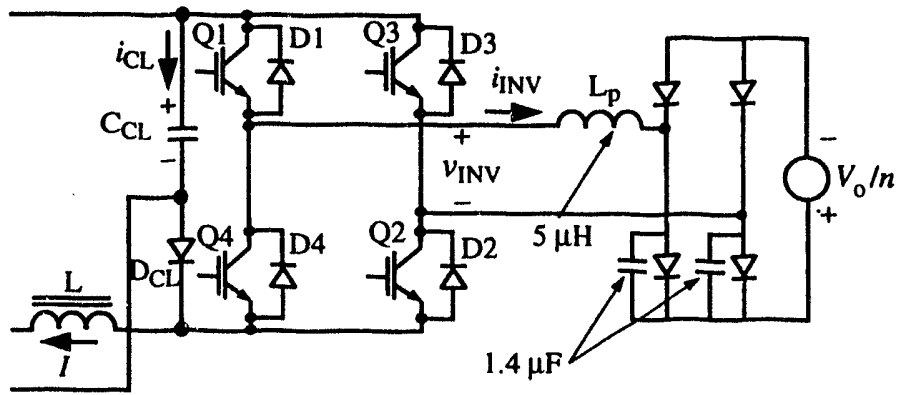

Fig. 8. Inverter realistic model, including transformer shield capacitance. tion and the additional inductance of the interconnecting busing, which was not included in the calculation.
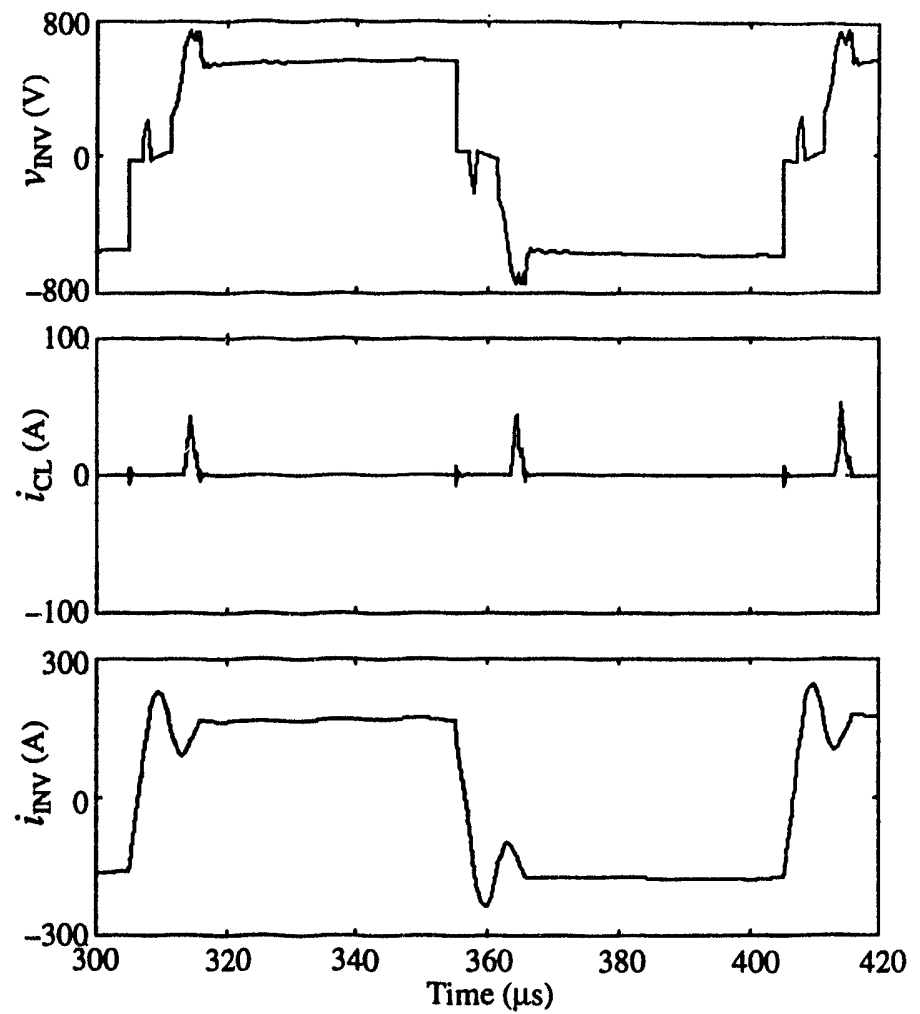

Fig. 9. Simulated inverter waveforms of $v_{\mathrm{INV}}, i_{\mathrm{CL}}$, and $i_{\mathrm{INV}}$ during normal operation near $100 \mathrm{~kW}$.
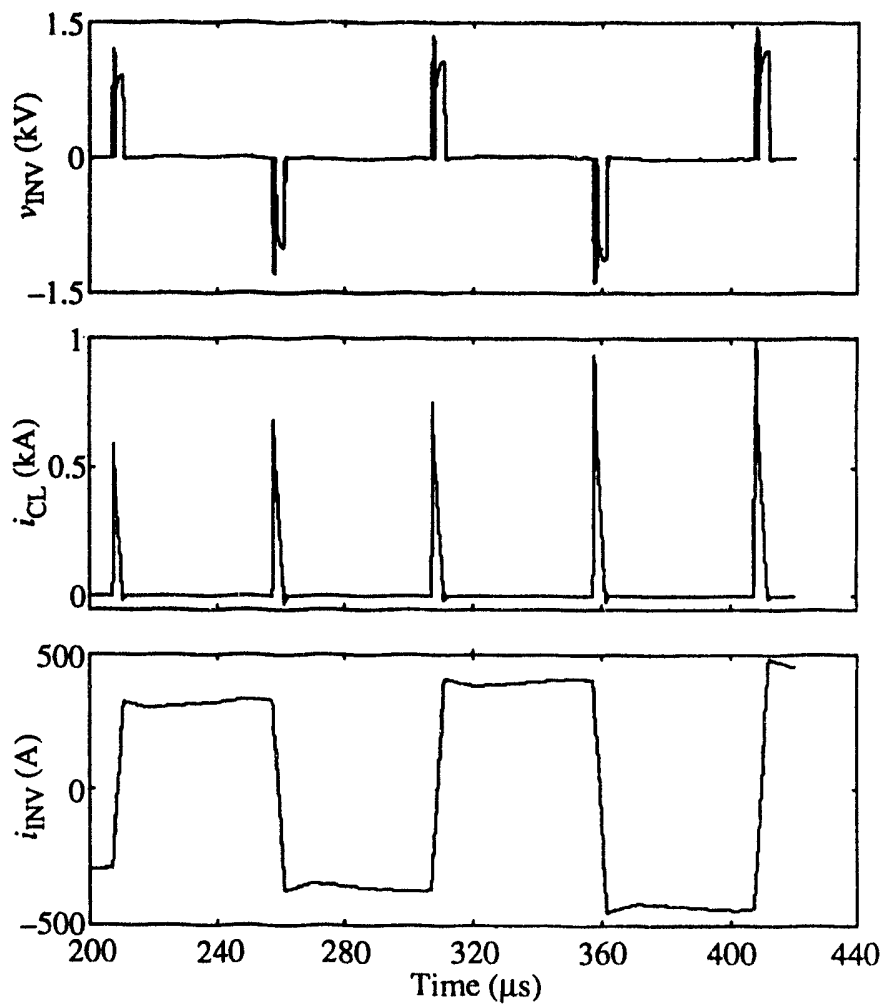

Fig. 10. Simulated inverter waveforms of $v_{\mathrm{INV}}, i_{\mathrm{CL}}$, and $i_{\mathrm{INV}}$ during an extended load short. 


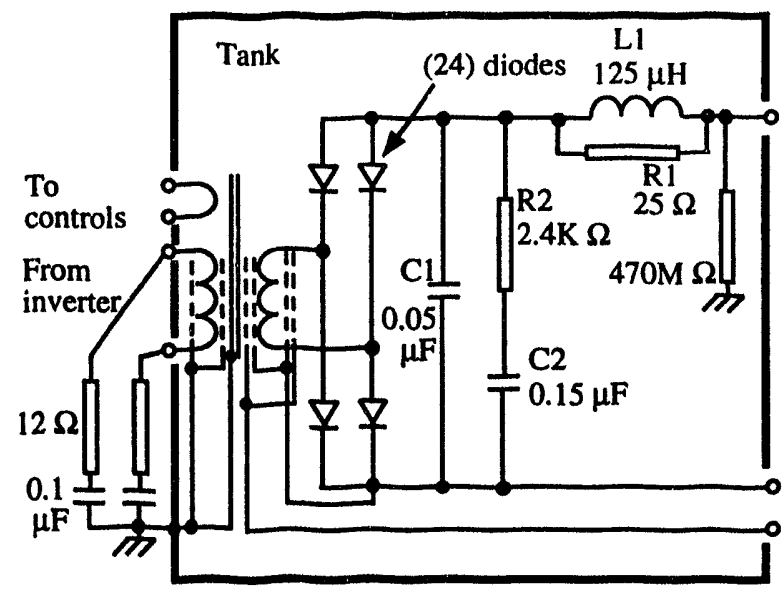

Fig. 11. Power circuit of the transformer/rectifier.

AC Losses: To control ac loss in the primary conductors, 0.010 -in. (25-mm)-thick copper foil was used. The number of layers was restricted to four for each primary winding to control proximity effect loss. For the secondary winding, \#16 AWG magnet wire in two layers was used. By the method of Carston [7], the ratio of ac-to-dc resistance is calculated to be 1.6 for the primary and 1.7 for the secondary winding.

Shielding: The transformer has three sets of electrostatic shields, each made from $0.005-\times 6$-in. $(0.013-\times 15.3-\mathrm{cm})$ copper foil. They are used to control currents during high-voltage arcs and to control common-mode currents at the output caused by the inverter switching. The design follows the rationale and methods of Stith [8].

Primary shields are used on both sides of each of the four primary windings. They connect to the tank wall through a wide, thin, copper bus (Fig. 4). Capacitive currents circulate within the shields during changes in voltage polarity. A low-inductance path from the shield to the regulator/inverter returns the capacitive currents and minimizes their introduction into the output. The $12-\Omega, 0.1-\mu \mathrm{F}$ network to ground at each transformer input provides damping of the currents that do not cancel.

Secondary shields are used on both sides of each of the two secondary windings. They connect to the positive dc output bus of each rectifier. As with the primary shield, capacitive currents circulate within the shields during voltage polarity changes. The shield protects the output rectifier diodes by providing a shunt path for the capacitive cl: rent to ground during a load arc.

A ground shield is used between each of the primary and secondary shields and is connected to ground near the e-beam gun load through the outer shield of the output coaxial cable. Current circulates in this shield during load arcs through the secondary shields and secondary windings. This eliminates arc currents in the primary windings and regulator/inverter circuit.

Efficiency: The calculated losses for the transformer at full power are $350 \mathrm{~W}$ for the primary windings, $550 \mathrm{~W}$ for the secondary winding, and $150 \mathrm{~W}$ for the magnetic core. The total loss is $1050 \mathrm{~W}$, a little over $1 \%$.

\section{Output Rectifier and Filter}

Four rectifier stacks are used in each transformer/rectifier tank. They are connected in a full-wave bridge configuration. Each stack consists of 24 diodes in series, with matching and protection components across each diode. The diodes are fast-recovery type rated at $85 \mathrm{~A}, 1000 \mathrm{~V}$, and $1.6 \mu \mathrm{C}$ reverse recovered charge.
The dc filter circuit at the output of the bridge rectifier consists of the main filter capacitor $\mathrm{Cl}$ and the damping network composed of the series circuit formed by $\mathrm{R} 2$ and $\mathrm{C} 2-\mathrm{C} 4$. The value of filter capacitance $\mathrm{Cl}$ is determined primarily by the time needed for the inverter to transfer between current polarities combined with the output voltage ripple requirement. The value of $0.05 \mu \mathrm{F}$ results in a calculated ripple of approximately $700 \mathrm{~V}(5.6 \%)$ peak-to-peak at $20 \mathrm{kHz}$ for one section and $150 \mathrm{~V}(0.30 \%)$ peak-to-peak at $80 \mathrm{kHz}$ for the entire power supply output. The value of the damping resistor $\mathrm{R} 2$ is selected to detune the second-order network formed between the filter capacitor $\mathrm{Cl}$ and the equivalent $500-\mu \mathrm{H}$ inductor in the regulator/inverter.

The output decoupling network composed of $L 1$ and $R 1$ in parallel is sized to prevent filter capacitor $\mathrm{Cl}$ from shorting out the output transmission-line matching network for the overall power supply. This avoids line reflections and their associated overvoltages during gun arcs. The line-matching network of $25 \Omega$ in series with $0.02 \mu \mathrm{F}$ is located in the output section, described next. The series combination of $R 1$ in each converter is $100 \Omega$, which prevents significant loading of the line-matching network.

\section{Output Section}

The output section contains the output transmission-line matching networks, output-current and voltage monitors, and output highvoltage connections. It provides the connections to the e-beam gun filament and bombardment power supplies located below, and to the e-beam gun located approximately $100 \mathrm{ft}(30 \mathrm{~m})$ away. The $25-\Omega$, $0.02-\mu \mathrm{F}$ network shown in Fig. 1 is a simplified representation of the output-cable line-matching networks. The output current monitor is a commercial, blade-type shunt with fiber-optic isolation circuitry added. The output-voltage monitor is a commercial, 10 000-to-1 voltage divider, also with isolation circuitry.

\section{Controls}

The block diagram of Fig. 12 shows the layout of the controls. A four-phase clock is used to synchronize the gating of the dc-dc converters. Each dc-dc converter has its own circuitry to generate the variable-duty-cycle pulse train to the regulator IGBT gates and the square wave to the inverter IGBT gates. The duty-cycle command to the regulator IGBT gates comes from the individual dc-dc converter outputvoltage feedback loop. This feedback signal is derived from the oneturn transformer winding output $\left(\nu_{\mathrm{TR}}\right)$ and the output current $\left(i_{\mathrm{o}}\right)$. This technique avoids having to measure at high voltages. The current in the regulator IGBTs $\left(i_{\text {REG }}\right)$ also is used in the feedback circuitry to provide a local current-moc' : control loop. This loop compensates for fast overloads. The voltage setpoint for each dc-dc converter comes from the overall power-supply voltage-control loop which uses pseudoderivative feedback with local limits [9]. The feedback for the overall power supply comes from a commercial, 10 000-to-1 voltage divider. A ramp generator provides a controlled rate of voltage rise during recovery from a cutback.

The controls also protect against arcs and extended load shorts. If the output current $\left(i_{0}\right)$ exceeds a threshold of approximately $10 \mathrm{~A}$, slightly above the maximum operating current, a cutback automatically occurs. The gates to all regulator IGBTs go to the off state, and the gates to all inverter IGBTs go to the on state. This condition lasts for approximately $250 \mathrm{~ms}$ to permit the arc to recover. At the end of this time, normal gating resumes, and the voltage setpoint is ramped up. If the current in one of the inverter clamping networks $\left(i_{\mathrm{CL}}\right)$ exceeds $\sim 40 \mathrm{~A}$, a cutback also occurs, causing an identical sequence. This fault protection is needed during an extended load short, where the output current may not exceed the 10-A threshold. As described before, the current in the clamping network is much larger during an extended load short than during normal operation. 


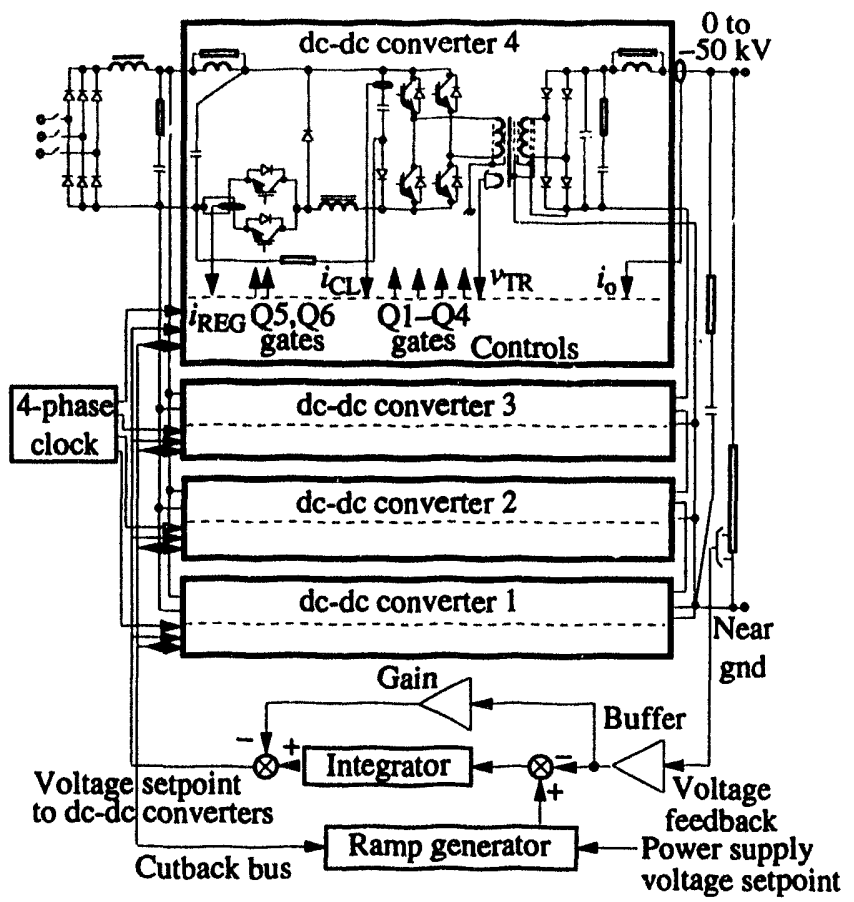

Fig. 12. Power-supply controls.

\section{PERFORMANCE}

The e-beam gun power supply described is operational. It has replaced a series-pass regulator-type power supply that uses a tetrode vacuum tube. Its output-voltage ripple and its dynamic performance during arcing are ne drly identical to that of the tetrode-regulator power supply. Its reliability is expected to be much better, but more operating time is needed to prove this.

The switching-type high-voltage power supply is much smaller than thyristor-controlled or tetrode-regulator types. Table II compares sizes of the switching-type e-beam power supply and the commercial e-beam gun power supplies installed at LLNL.

\section{TABLE II}

SIZE COMPARISONS OF SEVERAL TYPES OF POWER SUPPLIES

\begin{tabular}{ll}
\hline $400-\mathrm{kW}$ switching type & $170 \mathrm{ft}^{3}\left(4.81 \mathrm{~m}^{3}\right)$ \\
$250-\mathrm{kW}$ thyristor-controlled & $405 \mathrm{ft}^{3}\left(11.47 \mathrm{~m}^{3}\right)$ \\
$250-\mathrm{kW}$ tetrode-regulator & $490 \mathrm{ft}^{3}\left(13.88 \mathrm{~m}^{3}\right)$ \\
\hline
\end{tabular}

The power supply has been tested into a resistive load in excess of $400 \mathrm{~kW}$. It has a peak-to-peak voltage ripple at $-50 \mathrm{kV}$ output of $530 \mathrm{~V}$, or $1.1 \%$. The output harmonics are at primarily $360 \mathrm{~Hz}$ and $80 \mathrm{kHz}$. Waveforms of an inverter current and voltage are shown in Fig. 13 at near full load.

The power supply has a measured overall efficiency of $93 \%$ and a power factor of 0.95 at full power. Based on a combination of calculations, PSpice simulations, and measurements, more than $60 \%$ $(20.4 \mathrm{~kW})$ of the total loss $(34 \mathrm{~kW})$ is in the regulator/inverters. Of this amount, $52 \%(10.5 \mathrm{~kW})$ is lost in the IGBTs and $38 \%(7.7 \mathrm{~kW})$ in th snubber resistors. The overall power supply uses $55 \mathrm{gpm}(3.47 \mathrm{~L} / \mathrm{s})$ of $\mathrm{LCW}$ at a differential pressure of $80 \mathrm{psig}(552 \mathrm{kPa})$.

Electromechanical switches in parallel with the resistive dummy load were used to simulate gun arcing. Fig. 14 shows the power-supply output voltage and current waveforms during a simulated arc. The current is measured on the power-supply side of the line-matching network. The current is initially $500 \mathrm{~A}$ during discharge of the power-

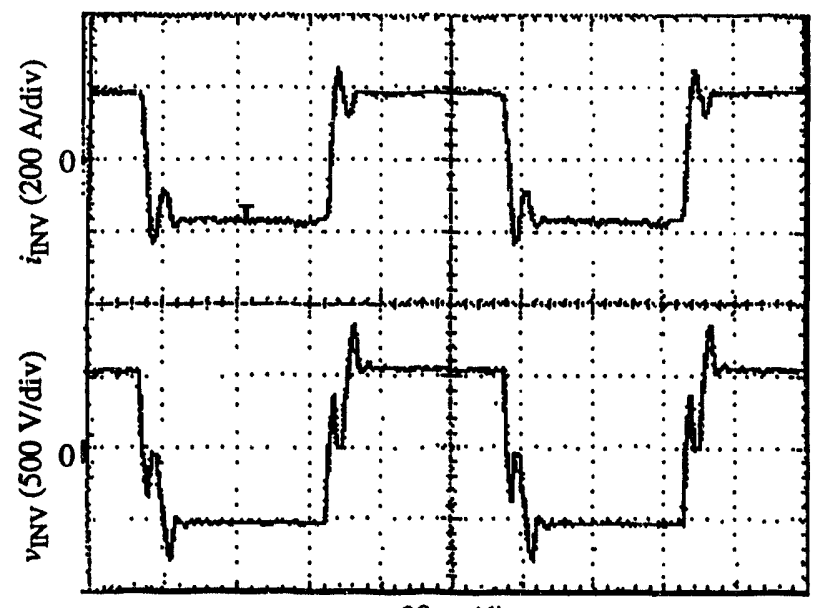

$20 \mu \mathrm{s} / \mathrm{div}$

Fig. 13. Output current and voltage of inverter at full load.

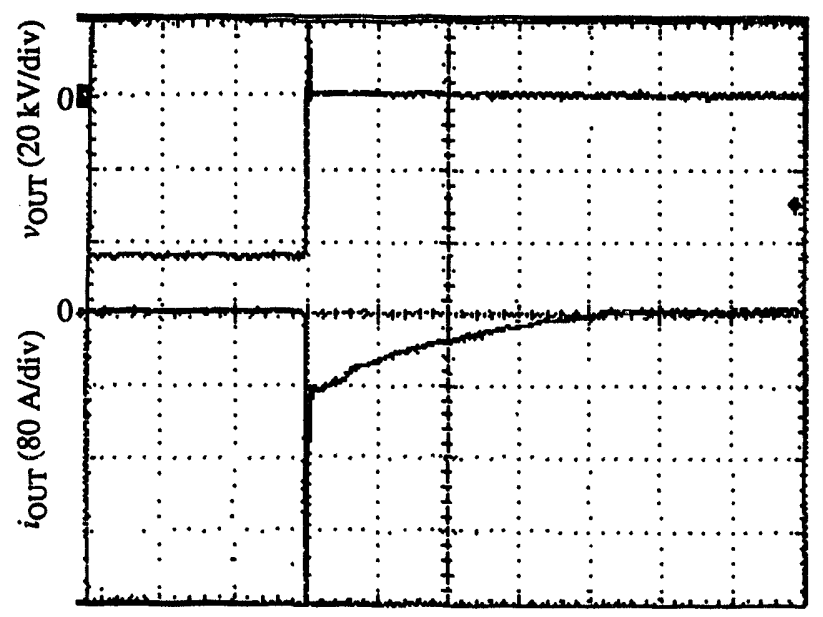

(a) $50 \mu \mathrm{s} / \mathrm{div}$

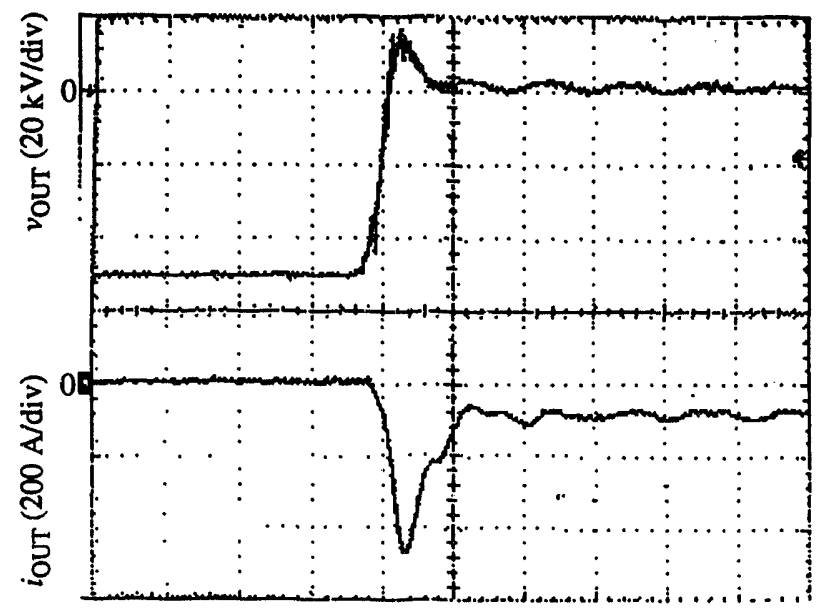

(b) $2 \mu \mathrm{s} / \mathrm{div}$

Fig. 14. Power-supply output waveforms during a simulated gun arc.

supply filter capacitors through the output decoupling resistors. The filter capacitors discharge to zero in approximately $2 \mu \mathrm{s}$. Approximately $75 \%$ of their stored energy is dissipated in the resistors, with the remaining energy transferred to the decoupling inductors. The current in the decoupling inductors then decays to zero in approximately $200 \mu \mathrm{s}$, forced by the voltage drop of the series diodes in the rectifier stacks. 
Fig. 15 shows the inverter output voltage, the clamping network current, and the inverter output current for one dc-dc converter during an extended load short. The power supply automatically attempts to ramp up the output voltage, and the inverter output current increases. The power supply cuts back when the clamping-network current exceeds $20 \mathrm{~A}$.

\section{CONCLUSIONS}

A 400-kW, switch-mode-type dc power supply for an electron beam gun has been successfully designed and built. It uses four modified current source type dc-dc converters, each rated at $100 \mathrm{~kW}$. The use of a shunt-type voltage clamping network, careful design of the transformer to reduce leakage inductance, and appropriate use of damping networks were some of the keys to its success. The switch-mode-type power supply has superior performance to the thyristor-controlled rectifier type and the series-pass vacuum-tube type power supplies. It is all solid state, it has high energy efficiency, and it is more compact. Its diode rectifier front end gives it a high power factor and low harmonics. Its current-source characteristic, its low stored energy, and its fast dynamic response result in excellent performance during load arcs. Future designs that exploit new, faster IGBTs with higher current ratings will make this type of power supply more cost competitive by reducing the number of $\mathrm{dc}-\mathrm{dc}$ converters required.

\section{REFERENCES}

[1] T. M. Anklam, L. V. Berzins, K. G. Hagans, G. W. Kamin, M. A. McClelland, R. D. Scarpetti, and D. W. Shimer, "Uranium AVLIS vaporizer development," Laser Isotope Separation, J. A. Paisner, ed., Proc. SPIE 1859, 1993, pp. 277-286.

[2] E. T. Calkin and B. H. Hamilton, "A conceptually new approach for regulated dc to dc converters employing transistor switches and pulsewidth control," IEEE Trans. Ind. Appl., vol. IA-12, no. 4, pp. 369-377, Jul./Aug. 1976.

[3] R. E. Miller, "Silicone transformer liquid: use, maintenance, and safety," IEEE Trans. Ind. Appl., vol. IA-17, no. 5, Sep./Oct. 1981.

[4] W. F. Praeg, "A high-current low-pass filter for magnet power supplies," IEEE Trans. Ind. Electron. Cont. Instrum., vol. EICE17, no. 1, pp. 16-22, Feb. 1970.

[5] E. T. Calkin and B. H. Hamilton, "Circuit techniques for improving the switching loci of transistor switches in switching regulators," IEEE Trans. Ind. Appl., vol. IA-12, no. 4, pp. 364-369, Jul./Aug. 1976.

[6] J. Schaefer, Rectifier Circuits-Theory and Design, p. 114, New York: John Wiley \& Sons, Inc., 1965.

[7] B. Carsten, "High frequency conductor losses in switchmode magnetics," High Frequency Power Conversion Conference Record, May 1986, pp. 155-176.

[8] S. Smith, Magnetic Components-Design and Applications, up 155-164, New York: Van Nostrand Reinhold Co., Inc., 1985.

[9] R. M.Phelan, Automatic Control Systems. Ithaca, NY: Cornell University Press, 1977.

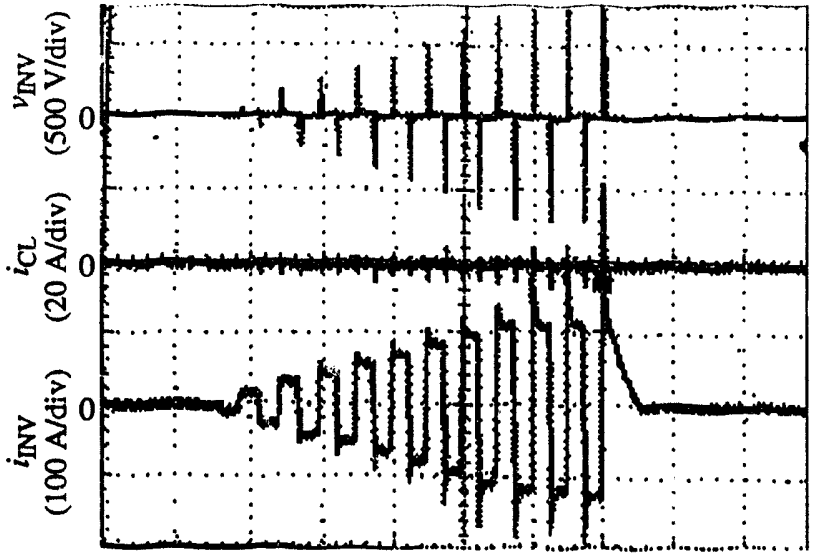

(a) $200 \mu \mathrm{s} / \mathrm{div}$

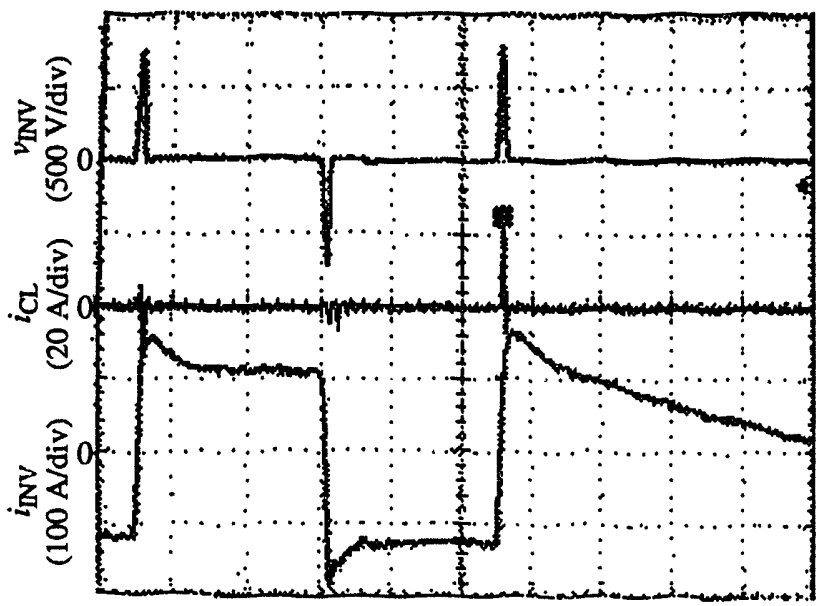

(a) $20 \mu \mathrm{s} / \mathrm{div}$

Fig. 15. Power supply output waveforms during an extended load short. 

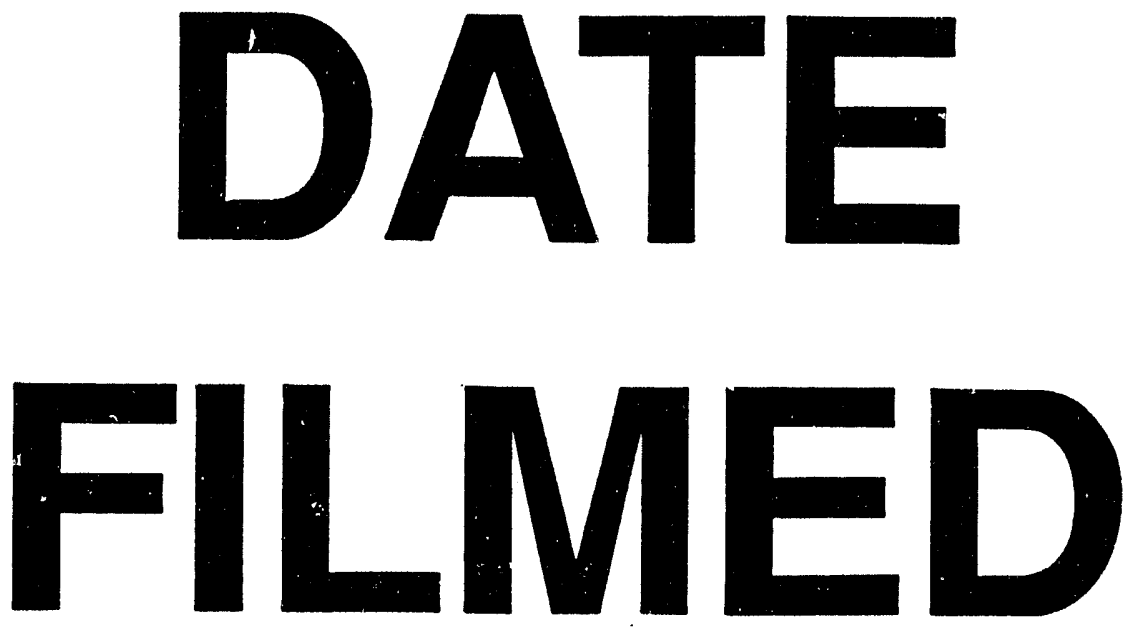

$10 / 17 / 94$
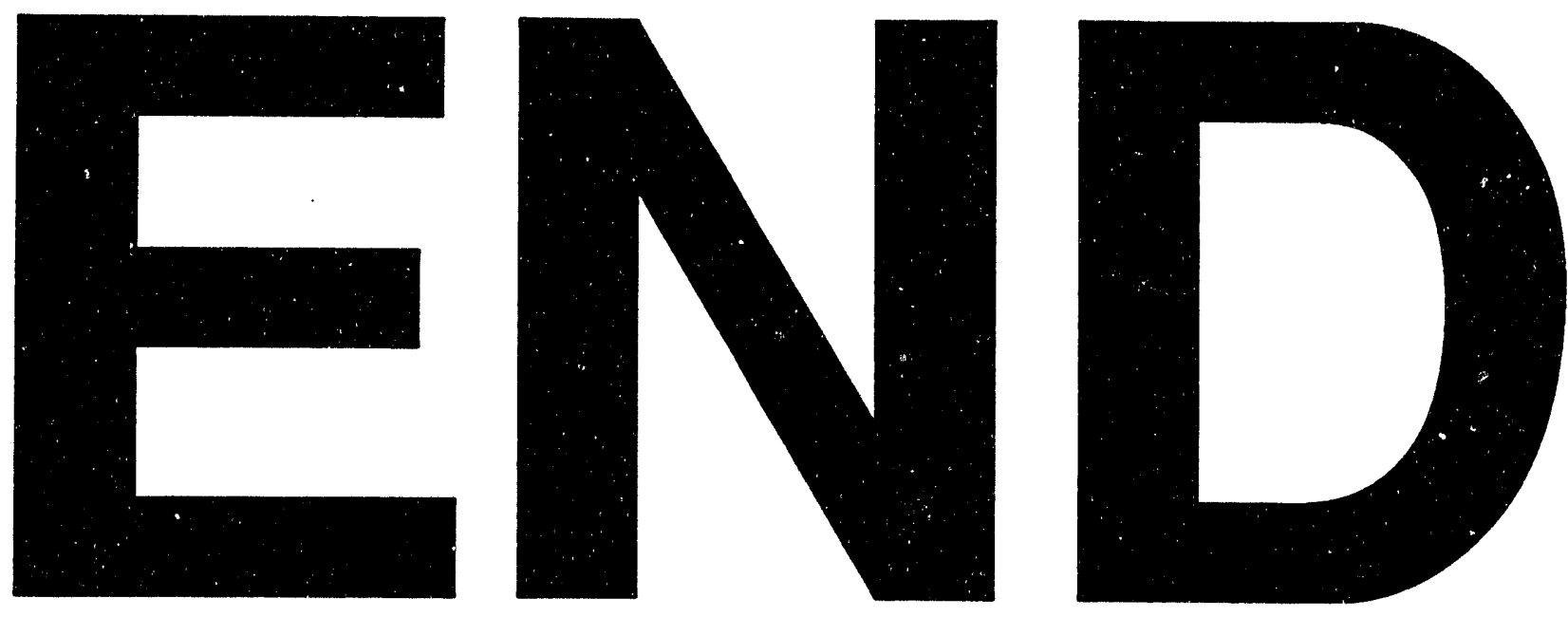
